\title{
Developing a set of quality criteria for community-based medical education in the UK
}

Philip Cotton

Section of General Practice, University of Glasgow, UK

Debbie Sharp

Department of Primary Health Care, University of Bristol, UK

Amanda Howe

Primary Care Group, Faculty of Health, University of East Anglia, UK

Caroline Starkey

Division of Community Health Sciences, St Georges, London, UK

Barbara Laue

Department of Primary Health Care, University of Bristol, UK

Arthur Hibble

Eastern Deanery, UK

\section{John Benson}

General Practice and Primary Care Research Unit, Department of Public Health and Primary Care, University of Cambridge, UK

WHAT IS ALREADY KNOWN IN THIS AREA

- Quality criteria for undergraduate teaching in general practice are not necessarily co-ordinated between medical schools or with postgraduate deaneries, and may conflict.

\section{WHAT THIS WORK ADDS}

- This is the first nationally derived list of criteria, for undergraduate and postgraduate practice-based teaching.

- They will allow benchmarking of local criteria against a nationally derived set.

SUGGESTIONS FOR FUTURE RESEARCH

- Evaluation of the utility of these criteria in practice particularly as components of the assessment of training practices.

\section{SUMMARY}

Context General practices educate increasing numbers of learners at various stages. Criteria for educational provision exist, but practices supporting learners at different stages and from different institutions might face different criteria.
Methods Criteria for practice-based teaching were developed at a workshop at a national conference. An online Delphi questionnaire invited educationalists to label these criteria as 'essential', 'desirable' or 'unnecessary' for 'occasional', 'intensive' and 'foundation year' teaching. Two rounds of the Delphi were completed. The views about the criteria of a range of stakeholders were 
explored using focus groups and telephone interviews.

Results We generated 76 criteria in five domains: physical environment, learning environment, tutor characteristics, patient involvement and departmental responsibilities.

Stakeholders' views differed concerning the merits of criteria and which should take greatest priority. None felt that developing such a list was inappropriate. They proposed no new criteria to add to those identified in the Delphi process

Conclusion To the best of our knowledge this is the first nationally derived list of criteria, capable of being used in both undergraduate and postgraduate practice-based medical education. These criteria can provide a benchmark against which to set local criteria.

\section{INTRODUCTION}

Primary care involvement in medical student education has widened. ${ }^{1,2}$ The number of medical schools has increased resulting in greater student numbers, with the consequence that at least one third of UK general practices are thought to be involved in student teaching. ${ }^{3}$ In postgraduate education a similar proportion of practices are involved in specialist training of general practitioners (GPs) and expanded teaching of doctors in the early (Foundation) years (Eastern Deanery, personal communication, May 2008). As models of service in primary care develop and diversify, and as the need grows for further educational capacity to support longer GP training and other community-based learning for relevant specialities, there are challenges for educational programme organisers and for those accrediting the quality of teaching and training to ensure effective use of all settings to deliver high-quality placements.

Evidence is improving on what constitutes good general practice teaching including important characteristics of teachers, factors that contribute to patients' support for teaching, and aspects of general practice teaching that students appreciate. ${ }^{4-6}$ Teaching provision has been associated with higher scores on organisational and performance quality indicators, and lower vacancy rates. ${ }^{7}$ Providing education is valued by GPs and staff, but competes with the demands of a commitment to a quality service in terms of time and resources. ${ }^{8}$ It can sometimes therefore take place 'on the run', and unanticipated teaching can present challenges for structured feedback and development. $^{9}$

Quality criteria for teaching and training in general practice have been set by both undergraduate departments and postgraduate deaneries, but these have not been explicitly co-ordinated, despite the fact that many practices undertake both activities. ${ }^{10-13}$ In the UK, the Postgraduate Medical Education and Training Board (PMETB) has responsibility for quality assurance of postgraduate teaching standards. The Royal College of General Practitioners (RCGP) sets professional standards and the deaneries quality-manage processes for selection and performance of training practices. The General Medical Council (GMC) sets standards for undergraduate medical education, assured through its Quality Assurance of Basic Medical Education (QABME) process. Nevertheless, detailed criteria for undergraduate teaching in general practice are currently determined and implemented locally, without national or regional co-ordination.

Teaching that meets established criteria may be the basis for investment, reward and appraisal. However, the process of accreditation may be costly and lack flexibility for change and circumstances. One US study surveyed medical schools and highlighted the importance of authentic criteria for ensuring the quality of undergraduate medical education and for the process of gathering evidence of compliance. ${ }^{14}$ In UK higher education, the Quality Assurance Agency (QAA) has produced a code of conduct on placement learning that includes institutional and teacher responsibilities. $^{15}$

General practitioners are a dispersed community of teachers accredited by more than one agency, sometimes with overlapping criteria. Furthermore, recent changes mean that a practice supporting learners at different stages, or from different institutions, might deal with differing criteria, and be subject to repeated quality monitoring, from different organisations.

The aim of this study was to develop a set of core quality criteria for teaching in general practice in the UK with evidence of acceptability to stakeholders in undergraduate and postgraduate education. The context was to seek to allow more co-ordinated supervision and support, and to reduce duplication in overlapping organisational systems.

\section{METHODS}

This study combined nominal group, focus group, interview, and Delphi approaches. ${ }^{16-18}$ The work was funded by SAPC, the Society for Academic Primary Care in the UK.

\section{Step 1: Workshop to generate criteria}

All heads of departments of general practice were asked to send representatives and where possible identify medical students, to attend a workshop to develop a list of criteria for teaching in general practice. The 44 attendees (Table 1) included staff from 20 medical schools in the UK and two in the Republic of Ireland; academics from one European medical school and four postgraduate deaneries; and students from five UK medical schools. 
Table 1 Profile of participants

\begin{tabular}{|c|c|c|c|c|}
\hline Stakeholder background & Workshop & $\begin{array}{l}\text { Delphi round } 1 \\
\text { (Invited) }\end{array}$ & $\begin{array}{l}\text { Delphi round } 2 \\
\text { (Invited) }\end{array}$ & $\begin{array}{l}\text { Stakeholder enquiry } \\
\text { (Invited) }\end{array}$ \\
\hline GP undergraduate teachers & $33^{*}$ & 44 & 44 & 35 \\
\hline Postgraduate deanery (GPs) & 4 & 5 & 15 & - \\
\hline Undergrad teaching administrators & 1 & 1 & 1 & 7 \\
\hline Students & 5 & - & - & 10 \\
\hline Patients & - & - & - & 10 \\
\hline Others & $1^{* *}$ & $2^{\star \star \star}$ & $2^{\star \star \star}$ & - \\
\hline Total & 44 & 52 & 62 & 62 \\
\hline
\end{tabular}

* 23 Medical School teaching leads (20 UK, two Republic of Ireland, one Mainland Europe), 10 'GP teachers'.

** Working on Modernising Medical Careers.

*** Working in a Strategic Health Authority (Workforce Confederation).

Through using a 'snowball' technique, participants generated, discussed and clarified criteria. ${ }^{19}$ In groups, participants clustered their criteria into domains generating 200 criteria in 24 domains. They then reviewed the criteria to identify perceived omissions, overlaps and to clarify terms.

In conclusion, participants' views on the merits and demerits of developing national criteria were recorded on flipcharts and in note form.

\section{Step 2: Electronic Delphi process}

Two authors (JB, PC) reduced the length of the workshop list to 102 criteria in six domains, by removing persistent duplications. An online questionnaire was then developed for a modified Delphi process ${ }^{20}$ presenting each criterion with the option to label it as 'essential', 'desirable' or 'unnecessary' for each of three levels of teaching:

1 Occasional - 'individuals or pairs of undergraduates taught in the practice several times a year'.

2 Intensive - 'a regular commitment to an ongoing programme involving a greater number of undergraduate students'.

3 Foundation year - 'teaching Foundation Year 2 doctors'.

Stylistic modifications were made after piloting in two academic departments. The final questionnaire, administered by an independent host (Priority Research Ltd, www.priority-research. com) took about 30 minutes to complete. This Delphi process sought stakeholders' views about criteria and assessed the degree of consensus. ${ }^{21}$

We identified 52 stakeholders (workshop participants plus representatives from other groups identified by the authors (Table 1)) including representatives from all UK medical schools and five academics working in postgraduate deaneries. For Round one we emailed an introduction to the project and a link to the online questionnaire, with two reminders over the following ten weeks. Forty-four stakeholders responded $(85 \%)$.

For Round two we annotated the questionnaire with the percentage of respondents in Round one who chose each response option. We emailed all 52 stakeholders from Round one, plus an additional ten volunteers from an email to members of the UK Conference of Educational Advisers (UKCEA) of postgraduate general practice educators. We sent two reminders, four weeks apart. Forty-four stakeholders including all ten UKCEA volunteers responded $(71 \%)$. All respondents were asked to rate the criteria for teaching in general practice from their own particular perspectives.

\section{Step 3: Stakeholder enquiry}

We explored the views of patients, GP tutors, undergraduate teaching administrators and students (Table 1) about the 102 criteria. We used focus groups and telephone interviews. Participants were given a four-page booklet containing the list of criteria and three trigger questions to prompt thinking before the focus groups or interviews. The questions were:

1 Are there any standards in the list that you find surprising or unacceptable?

2 Are there any that you consider essential for teaching?

3 Does the list include all of the standards you would wish to see?

Stakeholder enquiry groups were asked to highlight and discuss the criteria that they considered essential and the criteria they considered unnecessary, and to offer additional criteria.

We sought patient volunteers using a waiting room flyer in one teaching practice. The local research ethics committee advised that no approval was required. The city's primary care trust gave research governance approval. Seventeen patients expressed an interest, of whom 14 consented to participate and ten were able to attend one of two focus groups facilitated by a research associate (TQ). Participants' ages ranged from 30 to 84 years. Five were female. Discussions were tape-recorded and transcribed. A coding framework was developed and themes 
were identified and justified by illustrative quotations. ${ }^{22}$

A total of 35 GPs, working in four focus groups from two medical schools and facilitated by authors ( $\mathrm{AH}$ and $\mathrm{PC}$ ), gave their views on the desirability of the criteria. The tutors had a variety of experiences of undergraduate teaching and postgraduate training in general practice.

Following piloting, seven undergraduate teaching administrators, selected to achieve a geographical spread across the UK, were approached requesting telephone interviews. All seven agreed to participate and were asked the three trigger questions in the teaching criteria booklet (see above). Students were emailed and volunteers sought from one medical school. Ten fourth and final year students attended one of two focus groups.

Facilitators kept written notes and some participants returned the four-page booklet with their comments written against the criteria. Facilitators compiled reports and two authors (JB and PC) examined these data.

\section{Step 4: Generation of quality criteria list}

Questionnaire responses from the Delphi process were identical for 'intensive' and 'foundation year' teaching for all but three criteria (see Table 3), thus results were considered under two headings: 'occasional' and 'intensive/FY 2' teaching.

Criteria in Delphi Round two were classified as shown in Table 2. One criterion, 'contract with one medical school only' was deemed unnecessary by respondents.

In Delphi Round two, two of the criteria were not rated as unnecessary, desirable or essential for occasional teaching by any of the respondents. For these two criteria, the final rating is therefore based on responses in Delphi Round one (U1 in Tables 3 and 4).

$\mathrm{PC}$ and JB inspected the list of criteria and the data from the stakeholder enquiry, amalgamated overlapping criteria (only where assessed similarly by participants as essential or desirable) and re-phrased some criteria.

\section{RESULTS}

\section{The quality criteria list}

The educators' workshop generated 200 criteria in 24 domains. Review reduced the list to $102 \mathrm{cri}$ teria in six domains. Final reconciliation of overlapping criteria left 58 criteria in four domains (Table 3). These domains are:

\section{Physical environment \\ 2 Learning environment \\ 3 Tutor characteristics \\ 4 Patient involvement}

One domain generated in this study - Departmental responsibilities - does not describe quality criteria for practices and is presented separately (Table 4). The original list of criteria and detailed responses from each Delphi round are available at www.sapc.ac.uk.

\section{Educators' views on developing national criteria}

Workshop participants felt that national standards for teaching criteria could demonstrate and recognise competence, fostering improvements in teachers' and thus learners' experience. There was a general feeling that criteria were helpful, so long as they were negotiated between all parties, focused and realistically resourced. They could improve dialogue between national organisations, academic institutions and practices; avoid confusion between competing sets of criteria; support inter-professional working and personal development; avoid confusion between competing sets of criteria; and demonstrate successful teaching in practice. Such criteria might, however, be difficult to define and monitor, possibly being seen as an imposition on practices and forming a barrier to teaching.

\section{Stakeholder enquiry}

Several of those completing the Delphi question-

Table 2 Classification of scoring of criteria in Delphi Round two

\begin{tabular}{lll}
\hline $\begin{array}{l}\text { Percentage of respondents rating } \\
\text { criterion as 'essential' or 'desirable' }\end{array}$ & Amalgamation of two ratings & Final rating \\
\hline $\begin{array}{l}\text { No. respondents rating criterion 'essential' is }>50 \% \\
\text { total respondents }\end{array}$ & & Essential (E) \\
$\begin{array}{l}\text { No. respondents rating criterion 'desirable' is }>50 \% \\
\text { total respondents }\end{array}$ & $\begin{array}{l}\text { No. respondents rating criterion 'essential' } \\
\text { No. respondents rating criterion 'essential' and no. }\end{array}$ & Desirable (D) \\
$\begin{array}{l}\text { respondents rating criterion 'desirable' are both } \\
=50 \% \text { respondents }\end{array}$ & 'desirable' $>50 \%$ total respondents & Desirable (D)
\end{tabular}

${ }^{*}$ None of the amalgamated percentages were less than $50 \%$. 
Table 3

Quality criteria for community based education

Criteria

For occasional For intensive/

teaching

FY2 teaching

Physical environment

Student safety not compromised by practice location

Sufficient equipment for students to consult with patients

Space for students to consult on their own

Space for students to work alone/have tutorials

Basic protocols on using practice computer system including ethical guidance for access

to patient records

Student access to computer, printer, internet, email/university network, and relevant books

Video-recording and playback facilities available

Computerised searchable patient disease register

Suitable residential accommodation available

Travel time reasonable by public transport

Practice website for students

Learning environment

Learners made to feel welcome by practice

Support for teaching amongst practice patients

Demonstrates effective working of primary care team

Demonstrates adequate standards of record keeping

Preparation of the practice prior to student arriving, taking account of learning objectives

Provision of sufficient protected teaching time

A named education lead and deputy

A named management/administrative lead

Identification and consent of appropriate patients for teaching

Feedback from students (positive and negative) is used by practice

Evidence of enthusiasm to teach within the practice as a whole

Able to offer a wide range of clinical experience including work of non-doctor team members

Demonstrates use of audit in clinical practice

Explicit learning plan for each student

Shares department of general practice's values

List size per principal/non-principal 2000 max

Practice policy to support staff training

Consistently high-quality evaluation from students

Able to offer out-of-hours experience

$\begin{array}{ll}E & E \\ E & E \\ E & E \\ E & E \\ E & E \\ E & E \\ E & E \\ \text { E } & \text { E } \\ \text { E } & \text { E } \\ \text { E } & \text { E } \\ \text { D } & \text { E } \\ \text { D } & \text { E } \\ \text { D } & \text { E } \\ \text { D } & \text { E } \\ \text { D } & \text { D } \\ \text { D } & \text { D } \\ \text { D } & \text { D } \\ \text { D } & \text { D } \\ \text { U1 } & \end{array}$

Tutor characteristics

Enthusiasm/commitment to teaching

Awareness of importance of role modelling

Attends teacher development courses on an ongoing basis

Able to give constructive feedback

Able to undertake formative assessment

Awareness of ethical standards relating to teaching

Method of assessment are made clear to students

Able to ensure protected time for teaching

Willing to be evaluated/appraised as a teacher

Willing to reflect/act on student feedback

Evidence of competent communication skills

No serious upheld complaint

Willing to take responsibility for teaching schedule

Willing to prepare practice colleagues

Aware of curriculum/objectives of teaching

Aware of teacher/student assessment processes

Demonstrates high expectations of students

Commitment to the pastoral care of students

Understanding of basic educational theory/principles

Commitment to demonstrating reflective practice

Acknowledges students' needs

Willing to undergo peer review of teaching

Holds Membership of the Royal College of General Practitioners

Patient involvement

Adequate information for patients about teaching

Satisfactory patient consent/support procedures

Mechanism for dealing with a patient complaints

Involve patients who have chronic conditions

Appropriate reward for patients who attend specially for teaching 
Table 4 Quality criteria for organisers of community based education

\begin{tabular}{|c|c|c|}
\hline University department responsibilities & $\begin{array}{l}\text { For occasional } \\
\text { teaching }\end{array}$ & $\begin{array}{l}\text { For intensive/ } \\
\text { FY2 teaching }\end{array}$ \\
\hline Agreed teaching contract & $E$ & $E$ \\
\hline Adequate resourcing of teaching time & $E$ & $\mathrm{E}$ \\
\hline GP practice given a list of objectives & $\mathrm{E}$ & $\mathrm{E}$ \\
\hline Identify people within department to relate to & $\mathrm{E}$ & $\mathrm{E}$ \\
\hline Clarity of areas of responsibility/accountability & $\mathrm{E}$ & $\mathrm{E}$ \\
\hline Learning issues, methods and outcomes & $\mathrm{E}$ & $\mathrm{E}$ \\
\hline Example of how to meet requirements of the curriculum & $E$ & $E$ \\
\hline Method of acknowledging good teaching practices & $\mathrm{D}$ & $\mathrm{E}$ \\
\hline Curriculum based upon adult learning principles & $\mathrm{D}$ & $E / D$ \\
\hline Become involved in the continuum of teaching & $\mathrm{D}$ & $\mathrm{D}$ \\
\hline Explanation of different teaching practice models & $\mathrm{D}$ & $\mathrm{D}$ \\
\hline Vision/creativity - improve learning environment & $\mathrm{D}$ & $\mathrm{D}$ \\
\hline Awareness of other roles GP teacher may fulfil & $\mathrm{D}$ & $\mathrm{D}$ \\
\hline Reciprocal benefits for practice & $\mathrm{D}$ & $\mathrm{D}$ \\
\hline Tutors bridge the under/postgraduate divide & $\mathrm{D}$ & $\mathrm{D}$ \\
\hline Closed loops of communication between department and practice & $\mathrm{D}$ & $\mathrm{D}$ \\
\hline Practice visits to see all practice GPs & $\mathrm{D}$ & $\mathrm{D}$ \\
\hline Standards for payment of non-GP community teachers & $\mathrm{D}$ & $\mathrm{D}$ \\
\hline
\end{tabular}

$\mathrm{D} /$ Des $=$ Desirable or Unnecessary

E/Ess = Essential for Occasional: U1 = Unnecessary from Delphi round 1 results

For Intensive/FY: D/E = Desirable for Intensive, Essential for FY; E/D = Essential for Intensive, Desirable for FY

naire online and those in stakeholder groups commented on the large number of criteria. All advocated clarification, simplification and shortening.

Patients in particular found it difficult to engage with the criteria, seeing them as 'cryptic' and written in 'jargon', and lacking in background detail.

GP tutors proposed developmental staging of criteria, introducing them selectively for new teachers: 'not too strict too soon'. They felt that criteria should be 'specific, measurable, agreed, realistic and timely'. Some expressed the view that criteria for postgraduate teaching should not be imported uncritically for undergraduate use.

Some undergraduate teaching administrators were surprised to have been consulted. They believed that the most important aim was to give students a good experience in practice.

The students agreed that their experiences of learning in general practice had been varied. They expressed scepticism over quality assurance, seeing it as the 'University covering itself should anything go wrong'. They felt that it was important to take a global view of a practice's attributes and that too many standards could put off practices that might otherwise provide positive learning experiences.

Further qualitative data are presented under the five domain headings. The bulleted lists represent the range of comments made and do not prejudice or privilege any particular views. Not all stakeholder groups commented on all domains.

\section{Physical environment}

- Patients were supportive of the need for teaching space and facilities. They expressed the opinion that confidentiality should be made explicit, parti- cularly relating to student access to computer records.

- GP tutors rated highly physical space for student consulting and for teaching.

- Undergraduate teaching administrators felt that a room for students to consult on their own and computer and internet access were the most important aspects of the physical environment.

- Students felt that a private study area and access to a library were relatively unimportant and unrealistic.

\section{Learning environment}

- Patients felt that students should be exposed to a diverse range of clinical experience in practice. They saw it as important but obvious that learners be made to feel welcome and important that teachers be prepared. They saw student feedback as important and emphasised the need for time to be put aside for this.

- GP tutors felt that protected time for teaching and experience with non-doctor members of the team were the most important aspects of the learning environment. They also felt that support of the teachers by the practice team and a policy to support training of practice staff was important. Some tutors wondered whether a measure of patient care should be included.

- Students considered almost all of the criteria on the list as essential. They felt that learning plans were too fixed to enable learning that was largely experiential. They felt that a welcoming environment was important.

\section{Tutor characteristics}

- Patients' opinion was divided on the need for GP 
teachers to complete a formal course. They agreed that social and communication skills were far more important than course attendance.

- GP tutors felt that enthusiasm and commitment were the most important characteristics of tutors. Additionally, protected time and knowledge of assessment and evaluation were important.

- Undergraduate teaching administrators viewed most criteria as essential and prized enthusiasm for teaching and protected time for teaching. There was concern that being too prescriptive could damage the one-to-one relationship that is vital to teaching.

- The enthusiasm of the teacher and staff were rated very highly by the students who felt that the characteristics of the teachers were more important than the physical environment of the practice. They expressed some unease with teachers assessing students unless they have been trained in assessment, though they didn't think that courses necessarily produced good teachers. They felt that a commitment to pastoral care in community placements was important.

\section{Patient involvement}

- Patients regarded information about the knowledge level and experience of the student, as well as an explanation of what they should expect of the student, as essential. They felt that the notion of a 'reward' for involvement in teaching was patronising and that reimbursement of expenses was much more positive.

- GP tutors regarded provision of information to patients and satisfactory consent procedures as essential.

- Undergraduate teaching administrators had varied views on reimbursing patients' travel expenses and ranged from full recompense to none at all. They recognised the importance of valuing patients' contributions.

- Students felt it was important that patient expectations were realistic and that they should know the level of the students' experience.

\section{University department responsibilities}

- Patients regarded practice assessment visits as potentially unnecessary and impractical and students saw the criteria concerning departmental responsibilities as too vague and less important. However, GP tutors called for more clarity over departmental responsibilities and felt that practice visits with realistic quality assurance were essential.

- Undergraduate teaching administrators recognised the practical challenges to visiting practices but felt this was essential. Clear communication, including early identification of teaching dates, was important. Some mentioned the importance of thanking practices for teaching.

\section{DISCUSSION}

The list of quality criteria for community based medical education in the UK is not intended to be prescriptive, but to act as an evidence base for the development of local criteria which take account of variations in circumstances. Clearly there are some differences which are appropriate to different levels of teaching: for example, 'essential' ratings for occasional teaching were principally in the 'tutor characteristics' and 'learning environment' domains, whereas intensive and FY1 teaching also prioritised the physical environment. Students rated a practice-based library and study area as relatively unimportant, but prized a welcoming environment, enthusiasm of teachers and staff, and a commitment to pastoral care. The quality of interpersonal relationships may contribute to the experience of learning and teaching in practice in a way that is valued above the nature of the physical environment.

Within the domains there are characteristics that are measurable in advance of a learner joining the practice, others for evaluation of the learning experience, and others that are more aspirational. The domain of 'university department responsibilities' seems to identify reciprocal responsibilities rather than describe quality criteria for practices.

The strengths of the study are that it used a wide range of stakeholders, triangulated qualitative and quantitative data, iterated findings from one stage into the next, and created consensus in a visible and systematic way. Weaknesses include the very long list of criteria at each stage, which may have reduced participant capacity to discriminate consistently between criteria. The number of respondents to Delphi 2 was less than for Delphi 1, with a relatively low response rate of $44 / 62(71 \%)$. Although we spoke with a wide range of stakeholders, the overall number was relatively small, making it difficult to be certain that we had reached qualitative theoretical saturation when interpreting their views. ${ }^{6}$ In particular, the number of postgraduate educators was small and their views, elicited in the Delphi process, were not triangulated by qualitative data. The choice of locations for the stakeholder enquiry was pragmatic. The students were from one medical school and the nature of GP attachments, the mode of assessment and the proximity of attachments to major examinations varies between schools. These factors will influence the views expressed.

The study nevertheless is important because, to the best of our knowledge this is the first list of criteria explicitly developed for use in community based education at both undergraduate and postgraduate (FY) level. At a time when education in primary care is expanding, practices may teach students from more than one medical school, have varying levels of commitment, and may have undergraduates on placement while training 
postgraduates. Practices may have more than one teaching contract with different sets of associated quality criteria which may have resource implications depending on whether criteria are common, complimentary or conflicting. There is now, more than ever before, an important interface to be explored for practices that train postgraduate doctors and teach undergraduate medical students. The criteria for postgraduate GP training are not expected to clash with these criteria or complicate the accreditation of practices that teach undergraduates and train postgraduates. These criteria can provide a benchmark against which to set local criteria.

It remains to be seen whether the balance struck by our criteria between rigour and practicality is appropriate for practice-based teachers and how these criteria might best relate to other quality criteria and competency frameworks. The British Medical Association framework on competencies and attributes for GP educators ${ }^{23}$ relates mainly to tutor characteristics and at Level 1 there is considerable overlap with the criteria in this reported study. It is important to explore the utility of our criteria in practice, and whether they unify the criteria used by different institutions at undergraduate and postgraduate levels. The development of a set of quality criteria for community based medical education in the UK should create an interface for the accreditation of practices to teach undergraduates and train postgraduates. This needs to be taken up locally, regionally and nationally.

\section{Acknowledgements}

Dr Thelma Quince for the qualitative enquiry with the patient stakeholder group. Sue Stewart at SAPC for her support and assistance. Technical staff at Priority Research for their work on the electronic Delphi instrument.

\section{Funding}

?????? ??????????

\section{Conflicts of interest}

None.???????

\section{References}

1 Department of Health (2004) Medical Schools: delivering the doctors of the future. Department of Health Publications: London.

2 Department of Health (2005) Statistics for General Medical Practitioners in England: 1994-2004. Bulletin 2005.02. Department of Health Publications: London.

3 Society for Academic Primary Care (SAPC) (2002) New Century, New Challenges: a Report from the Heads of
Departments of General Practice and Primary Care in the Medical Schools of the United Kingdom. Royal College of General Practitioners: London.

4 Hay J, Acheson RM, Reiss BB and Evans CE (1980) Teachers in general practice: a comparative study. Medical Education 14(4): 277-84.

5 Benson J, Quince T, Hibble A, Fanshawe T and Emery J (2005) Impact on patients of expanded, general practice based, student teaching: observational and qualitative study. BMJ 331: 89-95.

6 Moorhead R, Maguire P, Siew and Lee T (2004) Giving feedback to learners in practice. Australian Family Physician 33(9): 691-5.

7 Gray RW, Carter YH, Hull SA, Sheldon MG and Ball C (2001) Characteristics of general practices involved in undergraduate medical teaching. British Journal of General Practice 51: 371-4.

8 Mathers J, Parry J, Lewis S and Greenfield S (2004) What impact will an increased number of teaching general practices have on patients, doctors and medical students? Medical Education 38: 1219-28.

9 Catchpole M, Albert E, Lake F and Brown T (2005) Teaching on the run. General practice training between consultations. Australian Family Physician 34(1): 47-50.

10 Allen J, Wilson A, Fraser R and Pereira Gray D (1993) The academic basis for general practice: the case for change. BMJ 307: 719-22.

11 Bain J, Scott R and Snadden D (1995) Integrating undergraduate and postgraduate education in general practice: experience in Tayside. BMJ 310: 1577-9.

12 Hays R (1997) Integration of undergraduate and postgraduate general practice education - does it work? Australian Family Physician 2(2): S83-6.

13 Jones R and Oswald N (2001) A continuous curriculum for general practice? Proposals for undergraduate-postgraduate collaboration. British Journal of General Practice 51: 135-7.

14 Kasselbaum DG, Cutler ER and Eaglen RH (1998) On the importance and validity of medical accreditation standards. Academic Medicine 73(5): 549-64.

15 QAA. www.qaa.ac.uk (accessed 20/05/07).

16 Lloyd-Jones G, Fowell S and Bligh J (1999) The use of nominal group technique as an evaluative tool in medical undergraduate education. Medical Education 33: 813.

17 Murray J and Hammons J (1995) Delphi: a versatile methodology for conducting qualitative research. Review of Higher Education 18: 423-36.

18 Cohen L, Manion L and Morrison K (2001) Interviews. In: Research Methods in Education (5e). Routledge Farmer: London, Chapter 15.

19 Newble D and Cannon R (2001) A Handbook for Medical Teachers (4e). Kluwer: Dordrecht.

20 De Meyrick J (2003) The Delphi method and health research. Health Education 103(1): 7-16.

21 Kuzel AJ (1992) Sampling in qualitative enquiry. In: Crabtree BF and Miller WL (eds) Doing Qualitative Research. Sage: Newbury Park CA.

22 Ritchie J and Spencer L (1994) Qualitative data analysis for applied policy research. In: Bryman A and Burgess $\mathrm{R}$ (eds) Analysing Qualitative Data. Routledge: London. Chapter 9.

23 www.bma.org.uk/ap.nsf/Content/Hubeducatorspayscalesandcompetencies (accessed 20/05/07)

Correspondence to: $\mathrm{Dr}$ Philip Cotton, 1 Horselethill Road, Glasgow G12 9LX, UK. Tel: + 44 (0)141330 8330; 
fax: + 44 (0)141 330 8331; email: p.cotton@clinmed.gla.a-

c.uk

Accepted $x x x x$ 